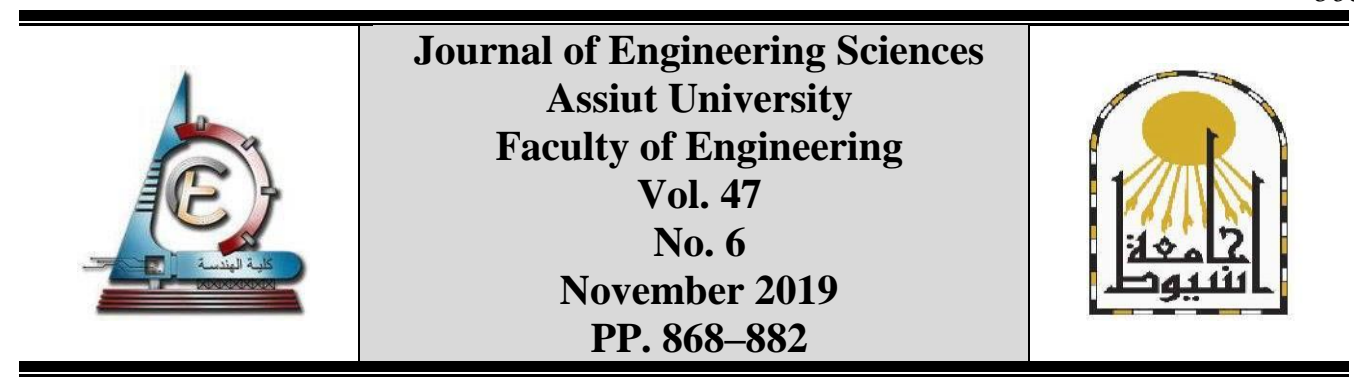

\title{
BIOCLIMATIC ARCHITECTURE FOR HERITAGE RESIDENTIAL BUILDINGS IN THE KINGDOM OF SAUDI ARABIA Environmental Design Approach Towards Providing Thermal Comfort in Future Buildings
}

\author{
Salma I. Dwidar \\ Architecture Department, Faculty of Fine arts, Alexandria University, Alexandria, Egypt \\ Architectural Engineering Department, Faculty of Engineering, Prince Sultan \\ University, Riyadh, KSA
}

Received 26 June 2019; Accepted 7 July 2019

\begin{abstract}
The Kingdom of Saudi Arabia has a remarkable historical heritage. It maintains architectural and urban evidence of great diversity in different parts of the Kingdom, and it reflects diversity due to climate variability and the topography and quality of the soil, resulting in the emergence of different architectural and urban styles, characterized by the diversity of traditional building designs and different building materials. Saudi Arabia is divided into five regions according to different topography and climate: central, northern, southern, eastern and western regions. Due to their exposure to surrounding environmental and climatic factors, traditional buildings are characterized by the uniqueness and diversity of their designs and the availability of thermal comfort. This research aims to study the impact of environmental and climatic diversity on the shape and design of traditional buildings in each of the five regions of the Kingdom, including the impact of traditional architectural treatments on the interior design of buildings and the extent of their ability to achieve thermal comfort. This shall provide an approach to maintain and develop traditional buildings to commensurate with modern times and set up foundations and criteria for achieving thermal comfort in the design of future buildings in each region
\end{abstract}

Keywords: Bioclimatic Architecture; Sustainable Building; Thermal Comfort; Architecture Heritage.

\section{Introduction}

Although the cultural conditions in the Kingdom of Saudi Arabia are almost identical and the economies are very similar, differences in building materials and climatic conditions like heat, wind, rain and topography in various parts of the Kingdom - whether it be desert or coastal areas, valleys and mountains - have led to the emergence of various types of traditional buildings and accommodation facilities. The expansion of construction and the evolution of life and its modernity led to the emergence of modern concrete buildings, which weren't designed with consideration of the different climatic factors for each region of the Kingdom. Instead, the use of air conditioners and cooling equipment is necessary to solve the 
Salma I. Dwidar, Bioclimatic architecture for heritage residential buildings in the kingdom

problem. This is why there is a need to study the climatic factors of each region and analyse its traditional buildings to reach the criteria of design that can be used when creating modern buildings within the Kingdom to benefit from the traditional factors in the modern design.

The research problem lies in the lack of knowledge of some designers regarding the influence of climatic factors upon the general characteristics of traditional architecture in the Kingdom and linking them to the formation and design of modern buildings within the Kingdom.

Modern architectural facilities lacking techniques for protection from the sun have been designed with large glass platforms that do not take into consideration the fundamentals of climate-adaptive design or natural climate controls for providing thermal comfort.

As a result, this research aims to study the impact of biodiversity and climate upon the form and design of traditional buildings to monitor and measure the impact of traditional architectural treatments used in each of the five regions of the Kingdom (central, northern, southern, eastern and western regions), which result from the effects of climate and environment on the interior design of buildings and the extent of their ability to achieve thermal comfort.

It must be attempted to find the foundations and criteria for achieving thermal comfort in the design of buildings in the future that combine modernity and adapting to the atmosphere of each region, where heritage is an extension and basis for the development of buildings in the future.

\section{Identifying the study area and factors influencing the division of the kingdom's areas and the general patterns of traditional architecture}

In this section, the study area will be identified - namely, the Kingdom and its boundariesand the factors affecting the division of the Kingdom from geographical and climatic factors and how they impact the general patterns of traditional buildings, as follows: [1]

\subsection{Brief introduction of the Kingdom of Saudi Arabia}

The Kingdom occupies $80 \%$ of the Arabian Peninsula and is surrounded by water from three directions: The Arabian Gulf from the east, the Red Sea from the west and the Arabian Sea and Indian Ocean from the south. The Kingdom extends between latitudes 56 and 34 East of Greenwich and longitudes 17 and 32 north, and, as a result, the climatic and geographical conditions vary.

\subsection{Factors affecting architecture and urbanization in the Kingdom of Saudi Arabia}

The geographical location affects architecture and urbanization in two ways. First, in that the location affects the climate (temperature, humidity, solar rays and wind), the nature of the area and the available building materials. The site, on the other hand, determines the neighbourhood, allowing the determination of the likelihood of expatriate influences.

Since the Kingdom is located in the desert region, most of its land is characterized by drought and high temperature, especially because the Kingdom is devoid of water bodies, which leads to a decrease in humidity. The land of the Kingdom is characterized by high average hours of sunshine, with a total of at least 3,300 hours per year. As for the wind, it is seasonal and usually carries north-western or south-western sands. As for the rain, it differs from one location to another, as shown in Fig. 1. As for the eastern and western 
parts that lie on the Arabian Gulf and the Red Sea, their climate is warm and humid, and all of the previous characteristics apply to them, as well.

\subsubsection{Dividing the Kingdom according to geographical factors}

The Kingdom of Saudi Arabia has been divided into five major regions (Fig. 2) in terms of geography, each of which having a traditional style of buildings influenced by neighbouring regions. It has a unique location that has made it a link between different types of styles of ancient civilizations, such as the Yemenite civilizations of Saba and Ma'in to the south, the Canaanite and Phoenicians to the north, the Assyrians and Babylonians to the east and the civilization of the Egyptians to the west. The proximity of the Kingdom of Africa resulted in it being affected by Africa in the southwest portion of the Kingdom. [2]

The Kingdom is divided according to geographical factors as follows:

Central region (Riyadh and Qasim— known as Najd): It is not affected by any of the other neighbouring civilizations and takes up $19 \%$ of the area of the Kingdom. The surface of the region varies between mountains, plateaus and plains dominated by the appearance of highlands

Western region (Mecca, Medina, Jeddah, Ta'if): Influenced by the patterns of traditional Egyptian Islamic buildings, the western region is characterized by its varied terrain, where the Tihama plains extend along the coast of the Red Sea between the Sarwat Mountains in the east and the Red Sea coast to the west in the form of a tape varying in width from one point to another, known as the mountains of Hejaz confinement

Eastern region (Dammam, Khobar, Dhahran): influenced by Assyrian and Babylonian civilizations, the Eastern region consists of several geographical sections, such as AlSamaan plateau, which is 400 meters above sea level and extends between the plateau, the Arabian Gulf, the plain of the East Coast, and Hana desert

Southern region (Jazan, Asir, Najran, Baha): influenced by the traditional Yemeni culture and traditional buildings in East Africa. It is one of the highest areas of the Kingdom above sea level, which includes mountainous areas (mountains of Sarawat and Hudaiba) that range between 1200 to $3000 \mathrm{~m}$ above sea level, the Tihama plains, and the coastal areas along the Red Sea coast

Northern region (Tabuk, Ha'il, Al-Jouf): influenced by the Canaanite and Phoenician civilizations, the northern region is geographically similar, as the appearance of highlands is prevalent and contains many valleys

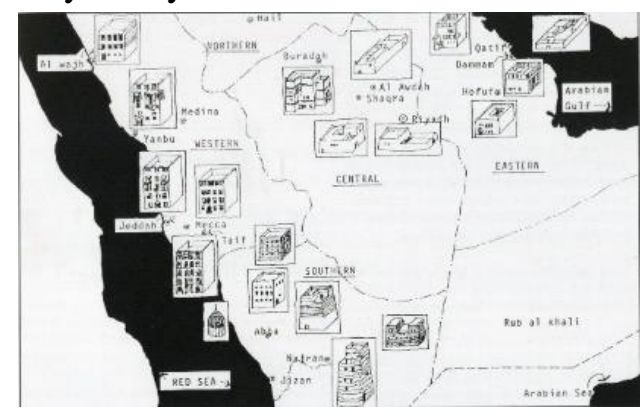

Fig. 1. Distribution of the different regions in the Kingdom 
Salma I. Dwidar, Bioclimatic architecture for heritage residential buildings in the kingdom ..........

2.2.2. Distribution of the Kingdom according to climatic factor: [3]

Climate is the result of many elements represented in the temperature associated with the movement of the sun, humidity, direction and speed of wind, rains and seasonality. A simplified approach is used to divide Saudi Arabia into the following four climatic zones:

1. Hot, dry region (Riyadh, Medina, Qassim, Mecca): Internal desert areas. The climate is hot and dry in summer with a temperature up to $45^{\circ} \mathrm{C}$; in Winter, it is between 10 to $20^{\circ} \mathrm{C}$ with weak rain and Spring is the season of rain

2. Hot, humid region (Jeddah, Jizan, Yanbu): Coastal areas. Temperature in summer is more than $40^{\circ} \mathrm{C}$, while in winter it varies between 27 and $30^{\circ} \mathrm{C}$. As for the humidity, the amount of rain falling on these areas varies from 24.4 to $77.4 \mathrm{~mm}$, and the prevailing wind direction is north-western

3. Composite climate zones (Dhahran, Qatif, Khobar, and Dammam): Region with internal coastal desert climate due to their location along the coast of the Arabian gulf. Extends toward the desert, which leads to climatic overlapping between the desert climate and coastal climate. This was reflected in the design of the traditional buildings within the region

4. Upland region (Abha, Taif, Khamis Mushayt): Characterized by having the heaviest rain. The temperature varies between 21 and $28^{\circ} \mathrm{C}$ in summer and $10-12^{\circ} \mathrm{C}$ in winter. (Fig.2)

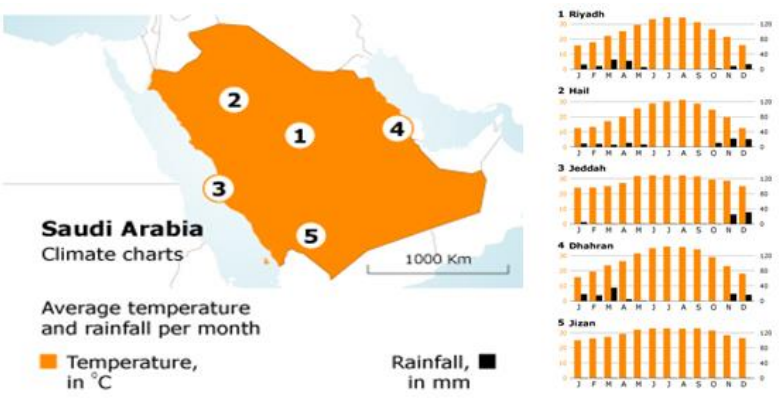

Fig. 2. Distribution of the Kingdom according to climatic factors

\section{Analitical study of traditional building types in different regions of kingdom and achievement of terminal confort}

According to the climatic conditions of Saudi Arabia, the buildings are exposed to a high temperature rise in the summer as well as direct thermal radiation on buildings and indirect emanating from other surfaces of neighbouring buildings or the surface of the earth. In short, the traditional buildings in different regions of the Kingdom that have succeeded in providing humanitarian needs will be analysed on the following basis:

1. Urban Design: Study and analysis of the urban fabric, roads and squares of each region

2. Architectural Design: Study and analysis of the design of traditional building structure and size (proportions and dimensions of the building), direction of the building, vocabulary and distribution of its spaces as well as study of the outer shell of the building (openings sizes, places and coverage)

\subsection{Traditional building patterns of the central and northern regions}

The traditional buildings in the central and northern regions will be analysed together for the great convergence of climate between the two regions. Also, when studying and analysing their buildings, we find great affinity in their buildings. The aim is to achieve the 
most effective urban and architectural solutions used in traditional buildings that adapt to the atmosphere of each region and achieve human thermal comfort.

First urban design: The urban fabric of the traditional cities and villages in the central region is suitable for the climate and topography of the desert region. It is compact, with narrow streets, narrow corridors and a few external openings, making the buildings closed from the outside and opens from the inside with internal courtyards to minimize surfaces exposed to weather conditions and provide shade covers for the largest possible area of building facades (Figs. 3, 4). [4]

Among the most important aspects of the urban treatments is that the buildings converge and are cohesive organically in the form of a single block, monolithic and adjacent to each other, with heights proportional to each other. Thus, they play a protective role for each other and alleviate heat and sun glare (Evan, 1980). Houses in their general shape seem to have a common height, as if they were erected simultaneously. This means that the wind does not pose a great danger, as it passes from the roofs of the buildings without finding any physical obstacles that make it veer towards a particular direction.

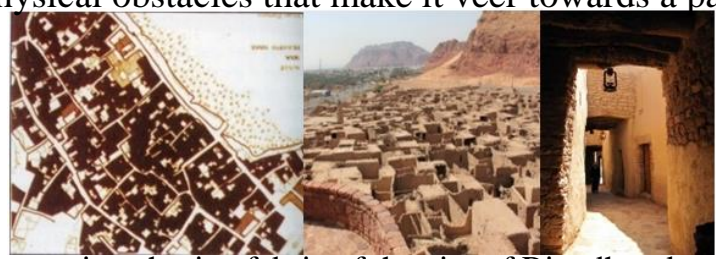

Fig. 3. The organic cohesive fabric of the city of Riyadh reduces heat intensity

Fig. 4. The organic cohesive fabric of the city of Ula reduces heat intensity

The urban fabric of the traditional cities and villages in the central region reflects the characteristics of traditional architecture. The mosque and market constitute the main arena of the assembly centre, from which the main roads and passages lead to the rest of the city and split to main and narrow roads to link centres and neighbourhoods.

\section{Second architectural design:}

\section{A. Design of traditional buildings:}

Building form: Building blocks are designed in these areas to minimize external surfaces exposed to solar radiation.

Building proportions and dimensions: Dimensions and proportions of the building affect the amount of solar radiation it receives, and, when analyzing the buildings in these areas, the basic design takes the rectangular shape with aspect ratio of 1:3 or 1:1.6, which is suitable for the buildings in hot desert regions (Fig. 5) [5].

Building orientation: The direction of the building affects the amount of solar radiation falling on the facades. [11] It is known that the southern facades are exposed to the highest solar radiation in winter and least in summer, while western facades are exposed to the greatest amount of radiation. The buildings are oriented east-west so that the largest surfaces are the northern-facing facades with a good distribution of the buildings' basic premises and the appropriate thermal and optical requirements. The mass is interspersed with internal courtyards, thereby increasing the surfaces of the facades exposed to the north (Fig. 5). Shadows are spread on the facades and on the floor of the yard (Fig. 6). [7] 


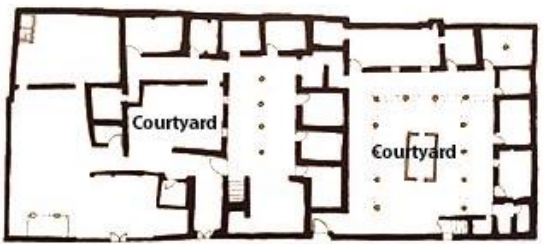

Fig. 5. Using the inner courtyard to increase the surfaces of the facades exposed to the north
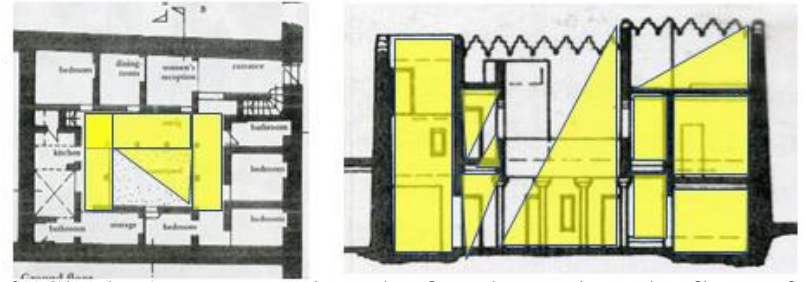

Fig. 6. Shadows are spread on the facades and on the floor of the yard

Design of building spaces and vocabulary: One of the most important vocabularies of buildings in the central region is the exposed internal courtyard, which helps to achieve thermal comfort. The layout of the building is distributed around one or more courtyards, which is a major space for social activities in the hot desert areas, as it affects the physiological state by providing protection from noise and external pollution and allows natural lighting. In addition, it works as a thermal regulator, as it cools the surfaces overlooking it with cold night radiation stored overnight and, during the afternoon, reduces the temperature of the air by 2 to $5^{\circ} \mathrm{C}$ (Fig. 7) [8].
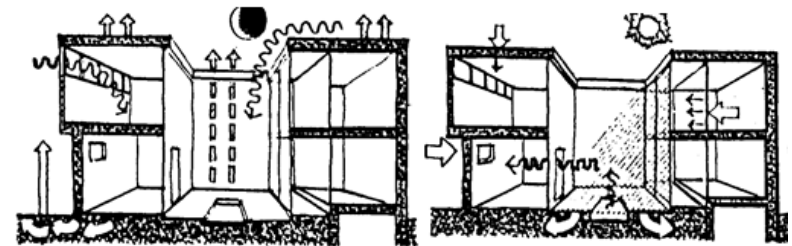

Fig. 7. The courtyard is a daytime thermal organizer that stores thermal energy during the day and radiates it at night to warm the atmosphere. The courtyard is a thermal regulator at night, where cold air is stored, and the courtyard surfaces radiate the amount of energy acquired during the day [6]

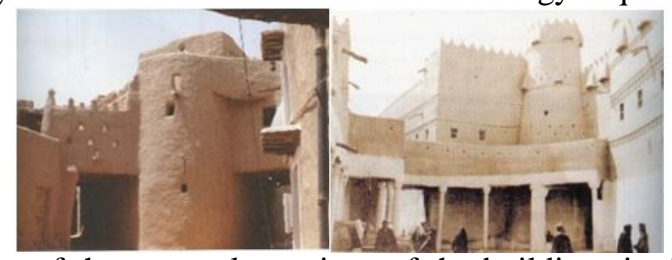

Fig. 8. The narrowness of the external openings of the buildings in the central region achieves thermal comfort inside the building

B. The outer shell of the building (Opening sizes, places, covers and orientation):

- The small number and narrowness of the external openings with the convergence of buildings protects the interior from external thermal transfer inside the building.

- The outer facades are protected from direct sunlight by external shading of the facades through the architectural formation of the building blocks and the narrow roads, which achieves a reasonable proportion of shading by some buildings upon others.

C. Building materials and construction methods: 
Local natural raw materials are used-mud mixed with water and soft straw to make bricks. The building material is of low thermal conductivity inside the building, and the structure is compatible with the hot, dry climatic conditions.

\subsection{Patterns of traditional buildings of the western region [1]}

The western region contains two types of climates due to its proximity to the Red Seacities far from the coast with the dry, hot climate of the desert (Medina and Makkah) and cities located on the Red Sea coast with a hot, humid climate (Jeddah and Yanbu).

First urban design: In general, the urban fabric of the western region is characterized by the density of architectural blocks and their proximity and connection to each other. It is interspersed with roads and winding alleys. Houses clinging to each other along with winding streets help to give houses a cold air stream that softens the atmosphere.

In the urban fabric of cities with a warm, dry climate, such as Madinah, a new spatial organization system has emerged - a system of "courtyards" rather than the "narrow lanes" system that is common in most Islamic cities. The difference is that the system of "narrow lanes" consists of the main street with secondary roads branching out and lined with housing, while the "courtyards" system consists of the main street with gates branching out, each of which leads to an open space called a "yard", topped by a shed. A group of buildings, ranging from 20 to 30 houses, are placed around the courtyard (Fig. 9). [9]

The urban fabric of coastal cities, where the heat and humidity are high, have taken the form a stripe on the coast to take advantage of the sea breeze (Fig. 10). The cohesion of the houses helped to form winding alleys, which were mostly beneficial paths for sea breeze.

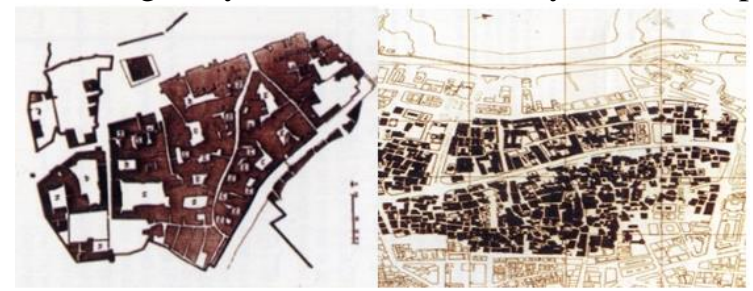

Fig. 9. The prevailing system of "courtyards" in the city of Medina

Fig. 10. Urban fabric in the western region of Jeddah

\section{Second architectural design:}

A. Design of traditional buildings

Building form: Building blocks are designed in these areas to minimize external surfaces exposed to solar radiation, as in previous areas.

Building proportions and dimensions: The basic design takes the rectangular shape with aspect ratio of $1: 3$ or $1: 1.6$, which is suitable for the buildings in hot desert regions, as in previous areas.

Building orientation: The buildings are oriented east-west so that the largest surfaces are the northern facades, reducing exposure to solar radiation, as in previous areas.

Design of building spaces and vocabulary: In the dry, hot climate areas (Madinah and Mecca), the general distribution of the house is in a large, open courtyard surrounded by rooms. The yard cools the rooms overlooking it with cold night radiation stored overnight, and, during the afternoon, reduces the temperature of the air 2 to $5^{\circ} \mathrm{C}$. 
Salma I. Dwidar, Bioclimatic architecture for heritage residential buildings in the kingdom .........

The buildings in the coastal cities are characterized by the availability of a wind catcher linked to the main stairwell for the purpose of spreading air throughout the house. In high buildings, the stairwell is considered a ventilator connected from the ground floor to the roof; this ventilation method provides comfort to the home population through evaporative cooling. The rooms are distributed around the stairwell (the vertical ventilation outlet) (Figs. 11, 12).

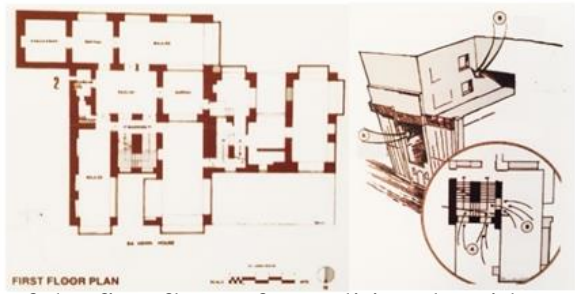

Fig. 11. Top-view of the first floor of a traditional residence in the western region

Fig. 12. Method of using the wind catcher in cooling houses

\section{B. The outer shell of the building:}

- The external wall facades are characterized by the large number of windows, which are covered by Rawashin or Mashrabiya - a type of projecting oriel window enclosed with carved wood - to allow the largest amount of air and moisturize into the interior spaces (Fig. 13). [10]

- The external facades are protected of direct sunlight by external shading.

- The narrow roads achieve a reasonable proportion of shading from the buildings' facades.

C. Building materials and construction methods: The buildings of the western region are characterized by their reliance on local environmental raw materials. The most important building materials are the following:

- Coral limestone was used in coastal cities such as Jeddah and Yanbu.

- Local timber available in the area from palm trunks and palm trees.

- The sludge was also used as a basic material in the making of the mortar to achieve the thermal comfort inside the buildings in the area. (Fig. 14)
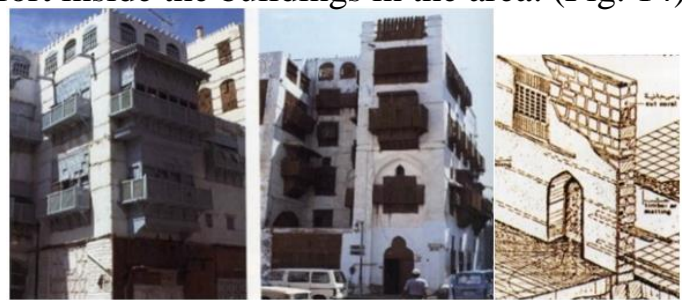

Fig. 13. Different types of Rawashin that cover the outer openings of buildings in the western region to protect them from the sun.

Fig. 14. Method of building external walls

\subsection{Patterns of traditional buildings of the eastern region}

The eastern region is dominated by hot humid climate despite the extension of the region from the coast of the Arabian Gulf eastward to the Empty Quarter desert in the west. This has affected the urban and architectural design in the region. [12]

First urban design: In the urban fabric of the eastern region, the streets are narrow and winding for climatic considerations, and the buildings are located closely to each other to prevent solar radiation and dust storms. They consist of one or two stories and are characterized by simplicity (Figs. 15, 16). 
Three urban patterns emerged in the eastern region cities as a result of their geographical location. The first pattern is the coastal urban fabric, which is striped, compact and parallel to the coast of the Arabian Gulf. The second pattern emerged in the cities located in the desert region near the Empty Quarter desert, a central urban fabric. The third pattern was linked to the agricultural land, which is known as the area of the oases, which is a compact urban fabric surrounded and permeated by farms.

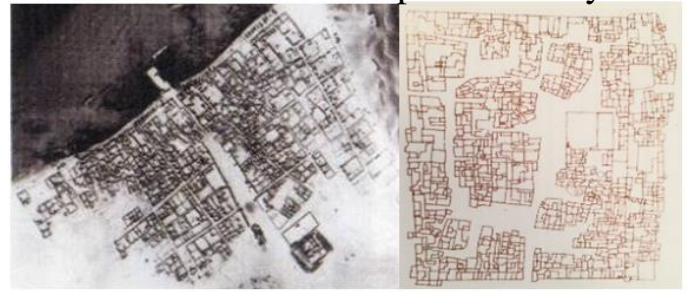

Fig. 15. Urban fabric of a city in the eastern region on the coast of the Arabian Gulf Fig. 16. Compact fabric interspersed with some public and private spaces

\section{Second architectural design}

\section{A. Design of traditional buildings}

Building form: Building blocks are designed in these areas to minimize external surfaces exposed to solar radiation, as in previous areas.

Building proportions and dimensions: The basic design takes the rectangular shape with aspect ratio of $1: 3$ or 1:1.6, which is suitable for the buildings in hot desert regions, as in previous areas.

Building orientation: The buildings are oriented east-west so that the largest surfaces are the northern facades, reducing exposure to solar radiation, as in previous areas.

Design of building spaces and vocabulary: The buildings are designed to contain more than one inner courtyard, which helps to increase the shade on the interior, with windows and openings overlooking it. The courtyard acts as a thermal regulator, as explained in advance (Fig. 17).

\section{B. The building envelope}

The buildings in the coastal areas are characterized by the large windows covered by rawashin, as in the western region, to let air in and moisturize the interior spaces (Fig. 18). Buildings in desert areas are characterized by small windows to reduce the transfer of heat from outside to inside buildings. Narrow roads provide a reasonable proportion of shading on buildings facades.

\section{Building materials and construction methods}

Local natural raw materials are used in the eastern region, such as mud, stoneware, hard rock, ash and materials extracted from the seabed, thus achieving thermal comfort within the buildings.

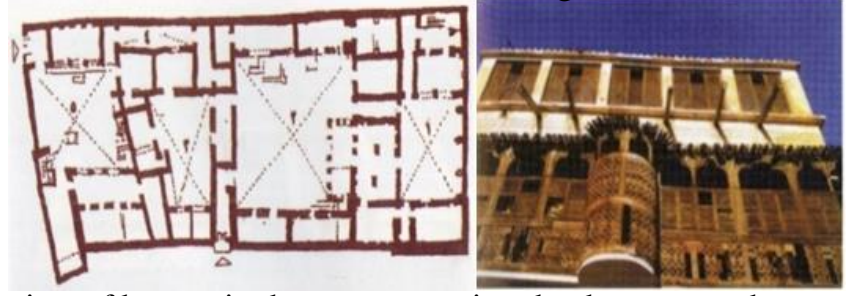

Fig. 17. Top-view of houses in the western region that have more than one inner courtyard Fig. 18. Using Rawashin to maintain the thermal comfort inside the building 
Salma I. Dwidar, Bioclimatic architecture for heritage residential buildings in the kingdom .........

\subsection{Patterns of traditional buildings of the southern region}

The topography of the southern region varies. As it includes mountainous and hilly regions, the highest in the Kingdom, and coastal areas along the Red Sea, southwest of the Kingdom. Hence, the region has two types of climate, upland climate and wet, hot climate in Tihama plains.

\section{First urban design}

The urban fabric of the Red Sea coastal plain of Tihama is scattered and characterized by the dispersal of the earthen buildings in the plains and on the edges of the valleys, according to the direction of the prevailing winds in the region, especially the western seaside (Fig. 19).

As for the urban fabric of the villages and cities in the high mountains and on the hills, it is compact, and the buildings are adjacent without large spaces between them with narrow and winding roads. The villages seem like a fortress of war due to security issues (Fig. 20)
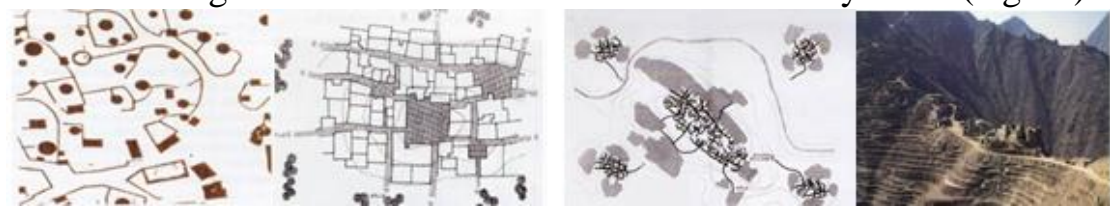

Figs. 19, 20. Compact urban fabric of the mountain villages

\section{Second architectural design}

\section{A. Design of traditional buildings}

Building form: The building blocks of the Tihama plains are circular in shape with a curved roof (Fig. 21). The horizontal projection of the curved surface as part of a ball represents the least external space exposed to solar radiation. The design of these buildings achieves the maximum thermal comfort in the southern region where the climate is warm and humid. Buildings in the mountainous and plateau region, where the temperature is moderate, are cylindrical or square.

Building proportions and dimensions: The buildings in the Tihama plains consist of a circular single story with diameter ranging from 3 to $5 \mathrm{~m}$. Other buildings have a square shape and consist of three to four stories. The buildings in the mountainous and plateau areas are rectangular with an aspect ratio of 1:3 or 1:1.6, as in the previous areas.

Building orientation: The orientation of huts located in the Tihama area is according to the prevailing wind trends in the plains area, which is mostly northwest.

Buildings in the mountain and the plateau regions are oriented according to the prevailing trend.

Design of building spaces and vocabulary: There are three traditional patterns in the region:

- The buildings in the plains of Tihama are often huts with a circular top view that take the conical shape in its façade. It has one or two entrances, one of which is to the west, where the gentle wind comes from the Red Sea (Fig. 21).

- Another type was built during the rule of Ottoman Adarsa in this region, which bears the Turkish character. The horizontal projections include internal courtyards similar to the buildings of the Arab Maghreb - the home of Adarsa.

- The traditional buildings located on the mountains using stone differ in their shape and exterior appearance. In the Viva Mountains, buildings are cylindrical, and, in 
Baha and Asir, buildings are square (Fig. 22). The design of the buildings in the hills, which were constructed of clay, depend the number of stories.

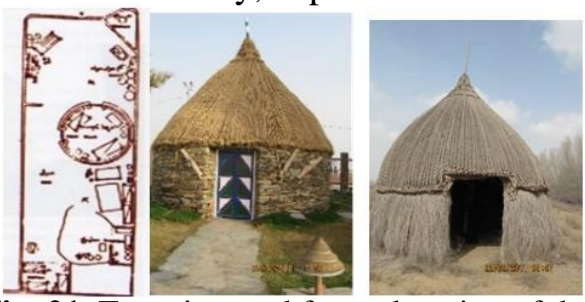

Fig. 21. Top-view and front elevation of the hut

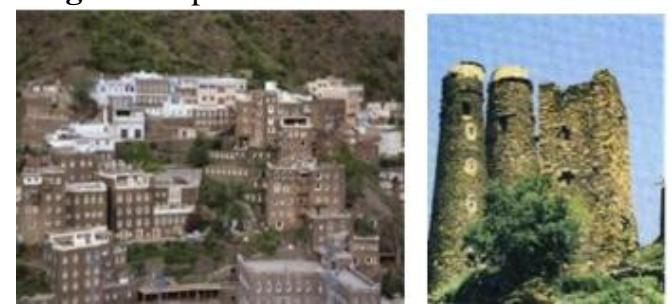

Fig. 22. Stone buildings in mountainous areas

\section{B. The building envelope}

- Buildings in the coastal area include two types. First, the huts had walls built of tree trunks and branches. Second, the buildings in the Turkish style are built of mud, have an internal courtyard with large windows, and the external walls have very few small windows.

- Buildings in the mountainous area: They are built with the stone available in the area, which are placed in a coordinated manner one by one. The gaps between the stones are then filled with chips of small rocks until all the spaces are sealed to prevent air from entering. Sometimes mud mortar is used to fill the blanks, and the external openings are often small (Fig. 22).

- Buildings in the plateau area: They are built with clay, and, as these areas are characterized by rain, gutters are added to the roof and windows are surrounded by white lime strips and pointed stones to drain the rain and protect the mud walls. The ground floor is sometimes built of stones. The climate is moderate in these areas, so windows are small to protect the building from rain (Fig. 23).

\section{Building materials and construction methods}

- The huts in the Tihama plains are built from the simplest common local materialstree trunks and branches. The internal surface is coated with a layer of clay and plaster and, thus, not affected by the heat of the atmosphere (Fig. 21). [13]

- Buildings on the plateau are built with clay extracted from the soil. The roofs are covered with palm trunks and pieces of stone and clay are scattered over it (Fig. 23).

- Buildings in the mountains are built of stones extracted from the mountains, and their roofs are also constructed from palm trunks.

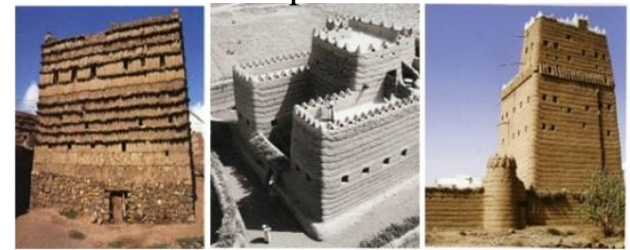

Fig. 23. Clay buildings in the plateau area 


\section{Design basic suitable for hot climate within the kingdom of Saudi Arabia}

Based on the previous analyses of the traditional buildings of all regions of the Kingdom and their success at providing thermal comfort within the buildings, a design basis has been reached, specifically for urban and architectural treatments, which can be used when designing future buildings within the Kingdom of Saudi Arabia. They are as follows:

\subsection{Design basis specific to urban treatments}

1. It is preferred that pedestrian walkways be in eastern and western directions, and that they be interrupted to provide shade and spread the best wind speeds within them

2. Pedestrian and mechanical movement should be separated for ease of climate treatment

3. It is recommended to reduce building heights to between two to four stories street segment from 1:10 to $1: 8$. The average wind speeds shall increase by $30 \%$, and air temperature shall drop by $0.7^{\circ} \mathrm{C}$

4. By increasing the percentage of ground occupancy to $85 \%$, the temperature of air passing through spaces increases, and, by adding courtyards of high altitudes to the building bodies, the occupancy percentage decreases. Furthermore, the average wind speeds increase through the surrounding spaces in the connected buildings' masses, and, so, the temperature of the air decreases

5. Previous experiments show the importance of placing buildings connected to each other in rows at a height of two floors to increase the flow of the desired wind

6. Intermittent shading of the corridors creates a sequence of shadows and light, which contributes to the reduction of the temperature up to $3.5^{\circ} \mathrm{C}$

7. The presence of multiple openings to different pathways leading to an open space helps the movement of the wind trapped between solid and void

8. Building non-energy-consuming architectural structures and using local building materials with their natural texture and color and developing them.

9. Small, repeated spaces are better than one large, open space

10.Trending towards the horizontal compact urban pattern based on the idea of a community in a hot region, and houses with internal courtyards to regulate temperature throughout the day in hot dry areas.

11. Orienting the urban mass and internal roads to allow the availability of shadows most of the day, taking into account the vertical and horizontal sun angles throughout the year

12. Based on the analysis of the hot climate, it is important to use trees within the urban fabric with high, to use limited water surfaces to lower the temperature and to increase the humidity within the air to reach a fractional climate suitable for life and work

\section{2. Design basis specific to architectural treatments}

1. Orienting the building so that it is perpendicular to the prevailing wind, which increases the amount of air inside the building and reduces the temperature

2. Orienting the building to attain the largest amount of shade possible

3. Using external finishing materials of light colors to help reflect the sun rays, which helps decrease the temperature within the building

4. Using local building materials that don't conduct heat and using materials that insulate heat

5. Using wind towers (wind catchers) and internal courtyards when designing the buildings to lessen the amount of heat within the building in the summer and to store heat in the winter 
6. The use of solar shutters depending on the angles of the sun falling on the different facades to lessen the amount of thermal radiation within the buildings

7. Decreasing the ratio of the envelope of the building to decrease the gain of heat in Summer and to decrease the loss of heat in Winter

\section{Identifying the contemporary buildings in different regions of the kingdom and achieving their thermal comfort}

Most of the contemporary buildings in the different areas did not take into account the interest in achieving the thermal comfort in the architectural and architectural design of contemporary buildings. We will review some of these buildings in various areas. The buildings that take into consideration the thermal comfort depends on the expensive modern materials, not the traditional methods that can be derived from the buildings. Heritage, traditional and inexpensive.

Central Region : The streets are wide and unshaded and the buildings have large openings that are not shaded too, which increases the high sense of heat inside the buildings. Forcing the use of large air conditioners in buildings and high consumption of fuel. Fig24

Western Region: Large apartment buildings are covered with glass that helps to increase light and heat penetration inside the building. Fig 25

Eastern Region: The streets are wide, unshaded, and large glass-roofed residential buildings that help increase light and heat penetration into the building. Fig 26

Southern Region: Despite the high temperature and humidity in the southern region of the Jezzan region, the buildings have large glass openings and wide streets, which increases the sense of thermal discomfort. Fig 27

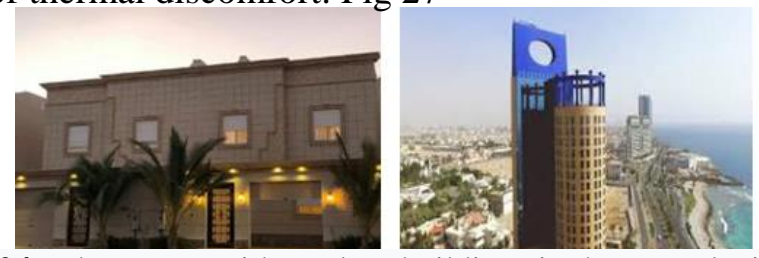

Fig. 24 Urban areas with modern buildings in the central Riyadh city

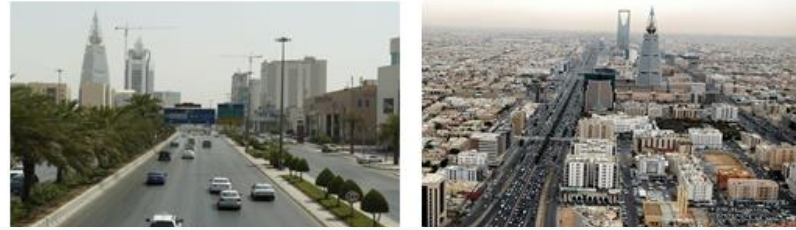

Fig 25 Residential villas and high rise buildings with large glass openings in Jeddah, Western Region

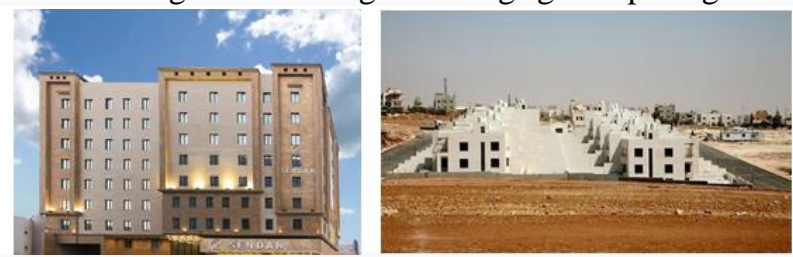

Fig 26 Villas and high rise buildings with glass openings and streets wide and non-shaded in the city of Jeddah Western Region

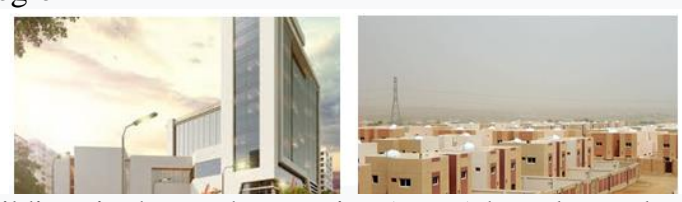

Fig. 27. Residential buildings in the southern region (Jazan) have large glass openings and wide streets 
Salma I. Dwidar, Bioclimatic architecture for heritage residential buildings in the kingdom .........

From the previous analysis, the contemporary buildings are similar in different regions of the Kingdom despite their different climates and topography. The aim of the research here is to take advantage of traditional methods when designing contemporary buildings in every region of the Kingdom. Taking into account the design principles of the architectural treatments mentioned in the previous item. Using these design foundations, the thermal comfort of the buildings will be realized and each area will retain its architectural character.

\section{Conclusion}

1. The areas characterized by the dry hot climate, such as the central and northern regions and some cities in the Western and Eastern region relied in their buildings' design on wrapping all elements of the house around the inner courtyard, reducing external openings or dispensing them. The design relied on an exposed internal courtyard for providing light and changing the air and for ensuring thermal stability inside the house. The walls are built of stone or clay (environmental materials available in each area) of large thickness, whereas the roofs are made of palm trunks covered with broken stones and mud

2. Areas characterized by a hot, humid climate, such as cities located on the Red Sea coast in the western or southern region or the cities along the coast of the Arabian Gulf in the eastern region have wind towers used for ventilation in the housing and are located in the middle of the house. Stairwells, which mediate the house, are used as towers and help create a wind current in the daytime from outside the house to inside the house. At night, the direction of the air stream in the tower changes and becomes like a chimney. Large openings are also which are covered by a mashrabiya, a window enclosed with carved wood latticework, which helps to Increase air movement and hydration internally

3. The regions that are characterized by having highland climate, which have moderate temperature, use environmental materials for building, and their traditional buildings have multiple stories and many small openings to provide thermal comfort internally

4. The urban fabric is a cohesive fabric with interspersed narrow and zigzag-like corridors, which is suitable for the hot-humid, dry-hot, or highland climates, which provides the thermal comfort in these areas

5. The study and analysis of the vocabulary of traditional buildings in the five regions, their relationship to the climate of each region and the extent of their provision for thermal comfort has reached design principles suitable for the hot climate in Saudi Arabia, and they can be used in the current age when designing modern buildings in the Kingdom

\section{REFERENCES}

[1] ALshakh, A., Shira, F., Aljatali, I. and Alhanatal,S., (2010). Architectural Heritage of The Kingdom of Saudi Arabia. Ministry of Municipal and Rural Affairs, KSA .

[2] Ishteeaque , E. Alsaid , F. (2008). The Native Architecture of Saudi Arabia. King Fahed national library cataloging-in-Publication Data, Riyadh.

[3] Talib, K.,(1984). Shelter in Saudi Arabia. Martin's Press, New York.

[4] Al Nouser, M. (1999). Characteristics of Urban Heritage in Saudi Arabia (Najed Region). Dara Kind Abdel Aziz Press, Riyadh.

[5] Al-Fagal K., (2002). Architecture and Environment in the Hot Desert Regions. Dar AlThaqafa for Publishing, Cairo.

[6] Evan ,M.(1980).Housing, Climate, Comfort. London. The Architecture Press,

[7] Al Wakil, Sh., (1989). Climate and the architecture of hot Region. The world of the book Press, Cairo. ed3 
[8] Konya A., (1984). Design Primer for Hot Climate. The Architectural Press, London

[9] Al Kaky , A., (2006). The urban fabric of Medina-Characteristics and components. Executive Committee for the development of the central region in Medina, Al Medina

[10] Al Hasin , M (2010). Al Madinah Al Munawwarah is a traditional urban structure. AlTurath Press, Kingdom of Saudi Arabia

[11] Brown, G. , (2001). Sun, Wind \& Light. John Wiley \&Sons Press, New York. ed 2.

[12] Hamoda , N., (2002). Solar radiation and architecture in desert areas. Symposium on Urban Development in Desert Areas and Building Problems. Ministry of Public Works and Housing, . Kingdom of Saudi Arabia

[13] Facey, W., (1997). Back to earth Adobe Building in Saudi Arabia. Al Turath, Riyad.

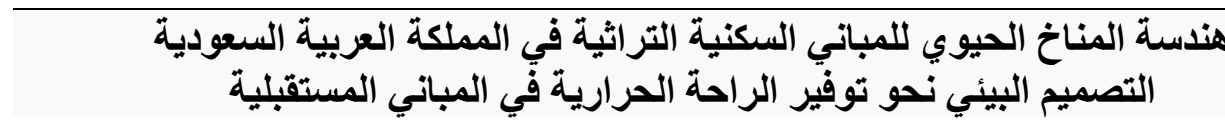

\section{ملخص البحث}

تمنلك المملكة العربية السعودية إرثا تاريخيا عزيقا ومميز ا، فهي تحتفظ بشو اهد معمارية وعمر انية تحظي بتتو ع كبير في مختلف

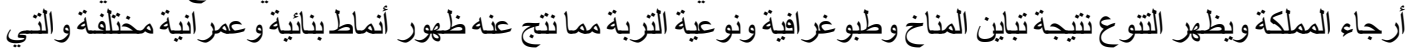

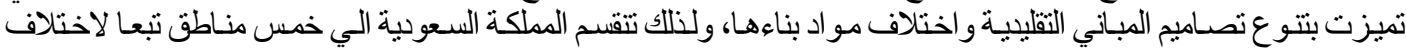

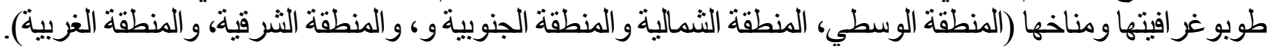

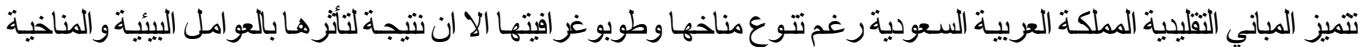

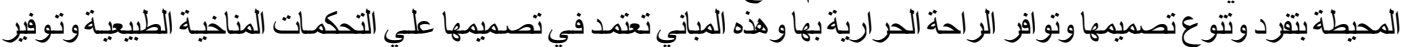

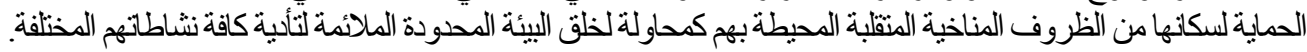

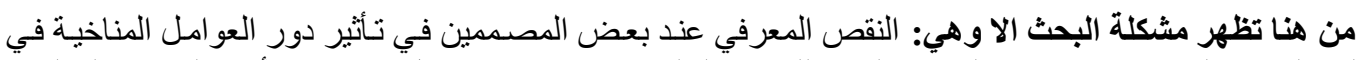
المملكة العربية السعودية في تحديد السمات العامة للعمارة التقليدية وربطها في تشكيل وتصميم الأبنية الحديثة بالمملكة

تم ظهور منشآت معمارية حديثة تفتقر الي أساليب الحماية من الطاقة الثمسية واشعة الثمس حيث صمدمت مبانيا

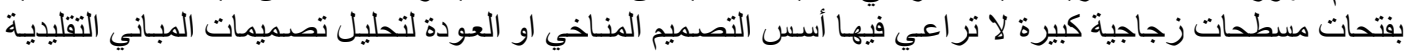

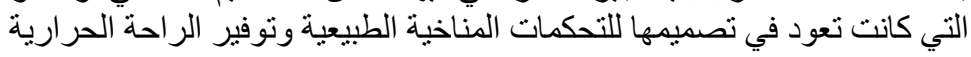

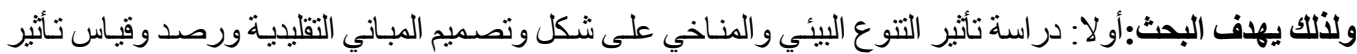

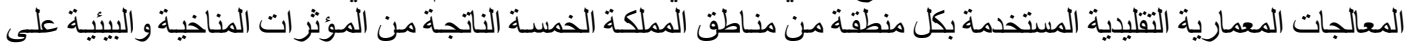

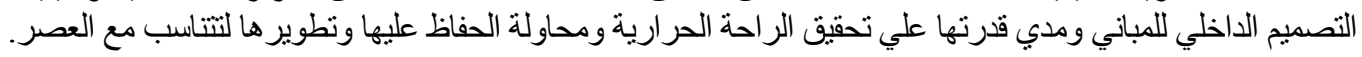

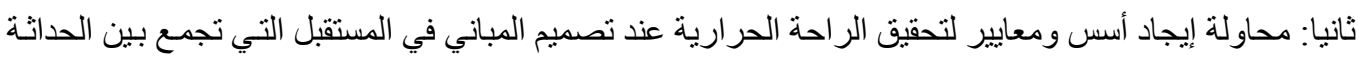

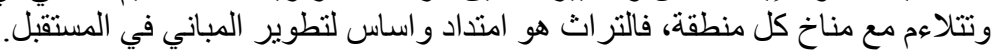

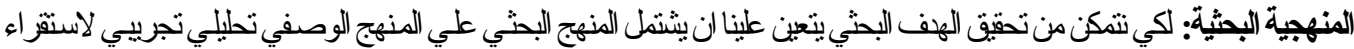

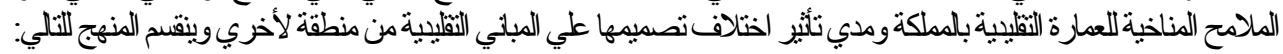

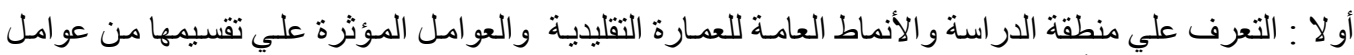

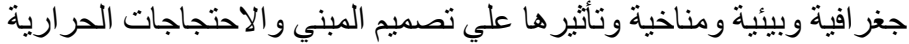

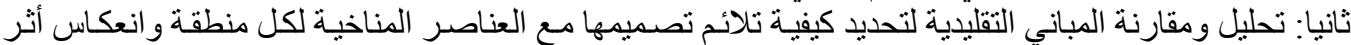

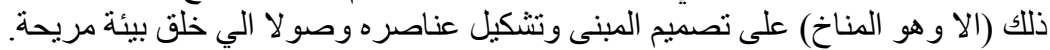

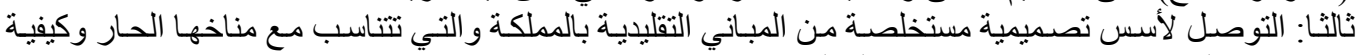
استخدامها مستقبليا عند تصميم مباني سكنية بالمملكة. 